\title{
Removal efficiency of phenol by ozonation process with calcium peroxide from aqueous solutions
}

\author{
Zhila Honarmandrad $^{1} \cdot$ Neda Javid $^{2} \cdot$ Mohammad Malakootian $^{3,4}{ }^{\mathbb{D}}$
}

Received: 13 October 2019 / Accepted: 15 December 2020 / Published online: 14 January 2021

(c) The Author(s) 2021

\begin{abstract}
Phenol has been introduced as a priority pollutant by the US Environmental Protection Agency. Advanced oxidation processes (AOPs) are one of the most efficient methods for removal of non-degradable organic pollutants in aqueous solutions. The removal efficiencies of phenol and $\mathrm{COD}$ under optimal conditions $\mathrm{pH}=3$, phenol concentration $=5 \mathrm{mg} / \mathrm{L}, \mathrm{CaO}_{2}$ concentration $=0.025 \mathrm{mg} / \mathrm{L}$, temperature $25^{\circ} \mathrm{C}, 1 \mathrm{~g} / \mathrm{min}$ ozonation rate and contact time $=90 \mathrm{~min}$ in synthetic and real samples (Zarand coal washing factory in Kerman) were obtained $97.8 \%, 87 \%$ and $80 \%, 65.4 \%$, respectively. The kinetics of phenol decomposition follows from the pseudo-first-order equation. Thermodynamic studies show that phenol decomposition with ozonation and calcium peroxide is an endothermic process. The use of ozonation process with calcium peroxide is an efficient method and can be recommended as a coefficient method for the removal of phenol.
\end{abstract}

Keyword Phenol $\cdot$ Calcium peroxide $\cdot$ Aquatic solution $\cdot$ Advanced oxidation $\cdot$ Catalytic ozonation

\section{Introduction}

Phenol is present in the sewage of various industries such as coal, resin, paint, fungicides and herbicides, textile, pulp, petrochemicals, pharmacy and plastics (Busca et al. 2008; Kidak and Ince 2007; Leitão et al. 2007). Phenol is fatal for fish at low concentrations $(5-25 \mathrm{mg} / \mathrm{L})$, and at concentration of about $0.5 \mathrm{mg} / \mathrm{L}$, it creates an unpleasant taste in drinking

Mohammad Malakootian

m.malakootian@yahoo.com

Zhila Honarmandrad

zhilahonarmandrad@yahoo.com

Neda Javid

n.javid1367@gmail.com

1 Department of Environmental Health Engineering, Sirjan School of Medical Sciences, Sirjan, Kerman, Iran

2 Department of Environmental Health Engineering, School of Public Health, Bam University of Medical Sciences, Bam, Iran

3 Environmental Health Engineering Research Center, Kerman University of Medical Sciences, Haft Bag Highway, Kerman 7616913555, Iran

4 Department of Environmental Health, School of Public Health, Kerman University of Medical Sciences, Kerman, Iran water. Phenol has been introduced as a priority pollutant by the US Environmental Protection Agency. The amount of phenol in drinking water should be less than $0.5 \mu \mathrm{g} / \mathrm{L}$. Industries that produce and consume phenol often produce polluted sewage with significant amounts of this chemical substance (0.1-10 wt\%) (Xiao et al. 2006, Idris and Sade 2002, Pimentel et al. 2008). The entry of phenol into sources of drinking water disinfected with chlorine compounds creates chlorophenol compounds that have important environmental and health problems, and creating an inappropriate flavor in water is obvious effect. Phenol enters the water resources via natural and artificial sources, and also, it is found in most chemical compounds due to its physical structure. Phenol is important due to its sustainability in the environment, solubility in water and health problems (Busca et al. 2008; Manojlovic et al. 2007; Roostaei and Tezel 2004).

Therefore, in order to prevent health and environmental hazards, treatment of phenol-containing wastewater is necessary before discharging into the environment. Advanced oxidation processes are the most effective technology for the decomposition and removal of hazardous, resistant pollutants and toxic substances in aqueous solutions. In recent years, advanced chemical oxidation processes have been proposed to treat sewage containing non-biodegradable or toxic substances as well as to treat sewage with very high concentrations of pollutants (Jamshidi et al. 2009; Sun et al. 2017). 
In advanced oxidation processes, hydroxyl radicals which are the most powerful oxidizing agents are used to decompose and remove pollutants. Different advanced oxidation processes have been used for the removal of organic pollutants from water and wastewater such as ozonation (Khan et al. 2010; Honarmandrad et al. 2017; Honarmandrad and Malakootian 2018), photo-fenton (Bautitz and Nogueira 2007), photocatalytic processes (Malakootian et al. 2016, 2015, 2013, 2018; Gharaghani and Malakootian 2017; Honarmandrad et al. 2017; Honarmandrad and Malakootian 2018) and the use of ultrasonic (Seid-Mohammadi et al. 2016). Advanced oxidation processes (AOPs) are based on physicochemical processes that produce in situ powerful transitory species, principally hydroxyl radicals $\left(\mathrm{HO}^{\circ}\right)$, by using chemical and/or other forms of energy, and have a high efficiency for organic matter oxidation; in fact, under proper conditions the species to be removed are converted completely to $\mathrm{CO}_{2}, \mathrm{H}_{2} \mathrm{O}$ and innocuous mineral salts. The principal mechanism of AOPs function is the generation of highly reactive free radicals. Consequently, combination of two or more AOPs expectedly enhances free radical generation, which eventually leads to higher oxidation rates (Agustina et al. 2005).

In recent years, combination processes such as ozone and hydrogen peroxide as Proxan (Qian et al. 2013; Honarmandrad et al. 2017; Honarmandrad and Malakootian 2018), ozone and ultraviolet light (Northup and Cassidy 2008) and ozonation in combination with Fenton process and catalytic ozonation process have been used (Roma et al. 2011). Calcium peroxide is an effective source for the production of hydrogen peroxide (Khodaveisi et al. 2011). The unique features of calcium peroxide include dissolving slowly in water and releasing oxygen molecules (Northup and Cassidy 2008). In addition, calcium peroxide decomposes in water and is converted to hydrogen peroxide and calcium oxide. Among the advantages of calcium peroxide, environmentally compatible, easy handling, low cost compared to other substances, long term and high impact can be noted (Cassidy and Irvine 1999).

Xiao et al. (2006) in China by using an extractive membrane reactor with silicone rubber, Pimentel et al. (2008) in France by using electro-Fenton with a carbon felt cathode, Tryba et al. (2003) in Poland by using $\mathrm{TiO}_{2}$-mounted activated carbon, Barrocas et al. (2017) in Portugal by using titanate nanofibers sensitized with $\mathrm{ZnS}$ and $\mathrm{Ag}_{2} \mathrm{~S}$ nanoparticles as novel photocatalysts and Sun et al. (2017) in China by using polypropylene hollow fiber were able to successfully remove phenol, and Malakootian et al. (2018) in Iran by using ozonation process with calcium peroxide for removal metronidazole and reactive blue 19 dye (Honarmandrad et al. 2017; Honarmandrad and Malakootian 2018).

The aim of this study is using ozonation process with calcium peroxide for removal of phenol from aqueous solutions.

\section{Materials and methods}

The research is experimental that was conducted in the second half of 2018 at the Research Center of Environmental Health Engineering in Kerman University of Medical Sciences. The stock solution with a concentration of $1000 \mathrm{ppm}$ of phenol was prepared with dissolved in deionized water on a daily basis. Then phenol was scanned by spectrophotometer, and its maximum absorption rate was obtained at a wavelength of $500 \mathrm{~nm}$. Concentrations of $5,10,15,20,25$ and $30 \mathrm{mg} / \mathrm{L}$ of the phenol stock solution were taken. Thereafter, the concentrations that were obtained with stock solution were blended with concentrations of $(0.025,0.05,0.075$ and $0.1 \mathrm{mg} / \mathrm{L})$ of calcium peroxide in $\mathrm{pH}(3,5,7,9$ and 11$)$, temperature $\left(25,35,45^{\circ} \mathrm{C}\right)$ and then were stirred by a shaker. Then it was ozonized at 30,60 and $90 \mathrm{~min}$. The solution was centrifuged. In the next step, the phenol absorption rate in the synthetic sample was read by the spectrophotometer.

In order to set the exact temperature, the chamber's temperature was continuously controlled by a sensor, which was placed inside the chamber. The sensor acted quickly when the temperature was changed. If the chamber temperature was reduced from the desired temperature, the electronic thermostat quickly turned the heater on and if it was increased from the considered temperature, the thermostat turned the heater off. A sensor was connected to the thermostat, which kept the temperature at 25,35 and $45^{\circ} \mathrm{C}$.

The amount of ozone of $1 \mathrm{~g}$ per minute was distinguished. The gas output from ozone generator was passed for $10 \mathrm{~min}$ from two containers containing $2 \%$ solution of potassium iodide. Both containers contained $250 \mathrm{ml}$ of potassium iodide solution. After $10 \mathrm{~min}$ of ozonation, $200 \mathrm{ml}$ of potassium iodide solution was taken. Thereafter, $10 \mathrm{ml}$ of sulfuric acid $2 \mathrm{~N}$ was added. In the following, the solution was titrated by using sodium thiosulfate $0.005 \mathrm{~N}$ until the disappearance of the yellow color of iodine. Thereafter, 1 to 2 drops of starch was added and the titration was continued until the disappearance of the blue color. At the end, the volume of consumption of sodium thiosulfate was recorded. The ozone produced was determined from Eq. (1). The kinetics of reactions and thermodynamics were obtained for the synthetic sample. The schematic figure for the experimental setup is shown in Fig. 1 .

Real sample was prepared by Zarand coal washing factory in Kerman, and its quality was determined in terms of phenol content, and because its amount of phenol was low, a little amount of phenol was added in order to reach optimal conditions in the synthetic solution.

The experiments were repeated three times and the results were reported as mean. Data analysis was carried 


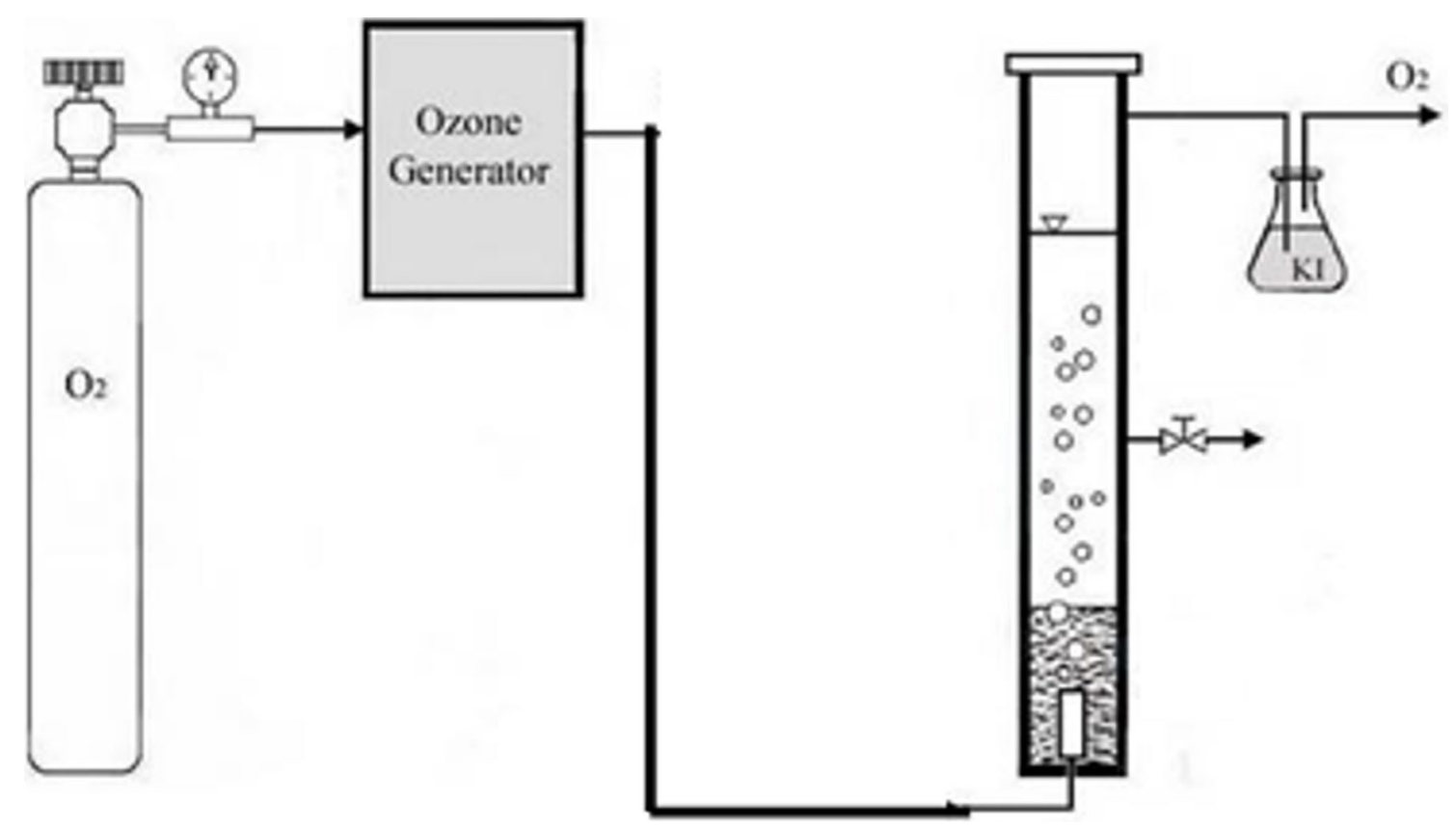

Fig. 1 Schematic figure for experimental setup

out using descriptive statistics. At the end, phenol removal efficiency was calculated from Eq. 2 (Sarmah et al. 2006):

Ozone concentration $\left(\frac{\mathrm{mg}}{\mathrm{L}}\right) i=\frac{(A+B) \times N \times 24}{T(\min )}$

$A$ : consumption of sodium thiosulfate for the first container $(\mathrm{mL}), B$ : consumption of sodium thiosulfate for the second container $(\mathrm{mL}), T$ : ozonation time (min), $N$ : normality of sodium thiosulfate.

Removal efficiency $(\%)=\frac{C_{i}-C_{f}}{C_{i}} \times 100$

$C_{i}$ : the initial concentration of phenol $(\mathrm{mg} / \mathrm{L}), C_{f}:$ the residue concentration of phenol $(\mathrm{mg} / \mathrm{L})$.

Phenol in the form of solid with purity of $99 \%$, calcium peroxide with purity of $98 \%$, sulfuric acid and sodium hydroxide were purchased from Merck Company. In this study, ozone-generating devices such as ARDA (model MOG-5 G/H France), air compressor (model FL25 Iran), pH meter (Model HANNA, Japan), flow meter, centrifuge (model-150) and spectrophotometer (model Schimadzu/ UV 1800 Japan) were used.

\section{Results}

\section{Effect of pH}

The results of tests for the effect of $\mathrm{pH}$ on removal efficiency of phenol from aqueous solutions are shown in Fig. 2.

90 min after the process with $\mathrm{pH}=3$, maximum removal efficiency of phenol in synthetic samples and real sample were 97.8 , and $87 \%$, respectively. Removal efficiency was decreased by increasing $\mathrm{pH}$ so that removal efficiency with contact time of $90 \mathrm{~min}$ and $\mathrm{pH}=11$ in synthetic sample was $45 \%$.

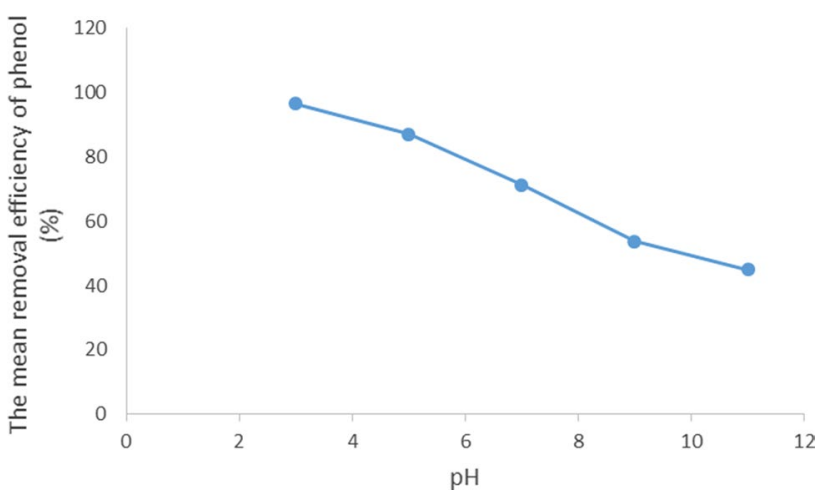

Fig. 2 Effect of $\mathrm{pH}$ on removal efficiency of phenol by ozonation process with calcium peroxide from aqueous solutions (phenol concentration $=5 \mathrm{mg} / \mathrm{L}, \mathrm{CaCo}_{2}$ concentration $=0.025 \mathrm{mg} / \mathrm{L}$, temperature $25{ }^{\circ} \mathrm{C}, 1 \mathrm{~g} / \mathrm{min}$ ozonation rate and contact time $90 \mathrm{~min}$ ) 


\section{Effect of calcium peroxide concentration}

The results of tests for the effect of calcium peroxide concentration on removal efficiency of phenol from aqueous solutions are shown in Fig. 3.

With calcium peroxide concentration of $0.025 \mathrm{mg} / \mathrm{L}$, removal efficiency of phenol in synthetic samples and real sample was 97.8 and $87 \%$, respectively. Removal efficiency was decreased when the calcium peroxide concentration was increased. When the amount of calcium peroxide was $0 \mathrm{mg} / \mathrm{L}$, removal efficiency of phenol in synthetic samples was $43.4 \%$.

\section{Effect of phenol concentration}

The results of tests for the effect of phenol concentration on removal efficiency of phenol from aqueous solutions are shown in Fig. 4.

Removal efficiency was decreased when the initial phenol concentration was increased so that maximum removal efficiency of phenol with phenol concentration of $5 \mathrm{mg} / \mathrm{L}$ in synthetic samples and real sample was $97.8,87 \%$ and minimum removal efficiency of phenol with phenol concentration of $30 \mathrm{mg} / \mathrm{L}$ in synthetic sample was $53.3 \%$.

\section{Effect of contact time}

The results of tests for the effect of contact time on removal efficiency of phenol from aqueous solutions are shown in Fig. 5.

It was observed that as contact time increases, the removal efficiency increases so that maximum removal efficiency of phenol with contact time of $90 \mathrm{~min}$ in synthetic samples and real sample was $97.8,87 \%$ and minimum removal efficiency

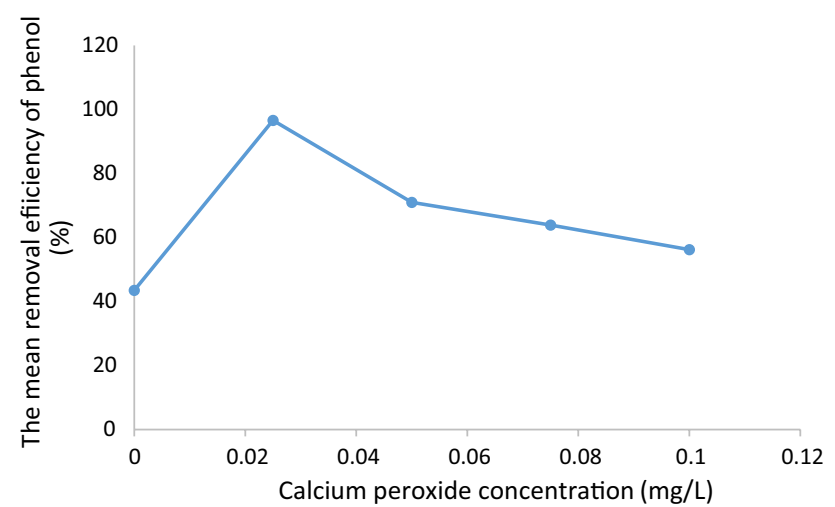

Fig. 3 Effect of calcium peroxide concentration on removal efficiency of phenol by ozonation process with calcium peroxide from aqueous solutions (phenol concentration $=5 \mathrm{mg} / \mathrm{L}, \mathrm{pH}=3$, temperature $25^{\circ} \mathrm{C}$, $1 \mathrm{~g} / \mathrm{min}$ ozonation rate and contact time $90 \mathrm{~min}$ ) of phenol with contact time of $30 \mathrm{~min}$ in synthetic sample was $77 \%$.

\section{Effects of ozonation process alone and ozonation process with calcium peroxide}

The effects of ozonation process alone and ozonation process with calcium peroxide for removal of phenol are shown in Fig. 6. The maximum removal rates by ozonation process alone and ozonation process with calcium peroxide were $43.5 \%$ and $97.8 \%$, respectively. The removal efficiency of ozonation with calcium peroxide was greater than ozonation process alone. According to Eqs. (3)-(6), calcium peroxide produced hydrogen peroxide and reacted with ozone to produce radical $\mathrm{OH}^{\circ}$ and radical $\mathrm{OH}^{\circ}$ has a great effect on phenol removal (Rahmani et al. 2018; WijannatrongI et al. 2013).

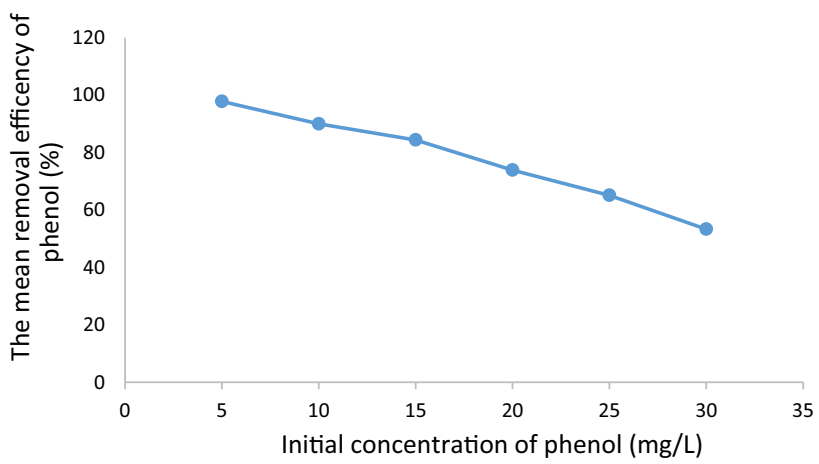

Fig. 4 Effect of initial concentration of phenol on removal efficiency of phenol by ozonation process with calcium peroxide from aqueous solutions $\left(\mathrm{CaCO}_{2}=\right.$ concentration $=0.025 \mathrm{mg} / \mathrm{L}, \mathrm{pH}=3$, temperature $25^{\circ} \mathrm{C}, 1 \mathrm{~g} / \mathrm{min}$ ozonation rate and contact time $90 \mathrm{~min}$ )

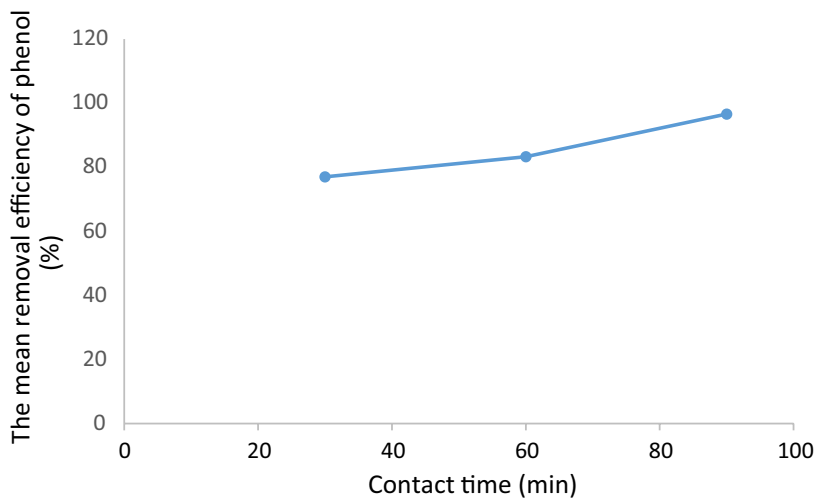

Fig. 5 Effect of contact time on removal efficiency of phenol by ozonation process with calcium peroxide from aqueous solutions (phenol concentration $=5 \mathrm{mg} / \mathrm{L}, \mathrm{CaCo}_{2}$ concentration $=0.025 \mathrm{mg} / \mathrm{L}$ and $\mathrm{pH}=3$, temperature $25^{\circ} \mathrm{C}$ and $1 \mathrm{~g} / \mathrm{min}$ ozonation rate) 


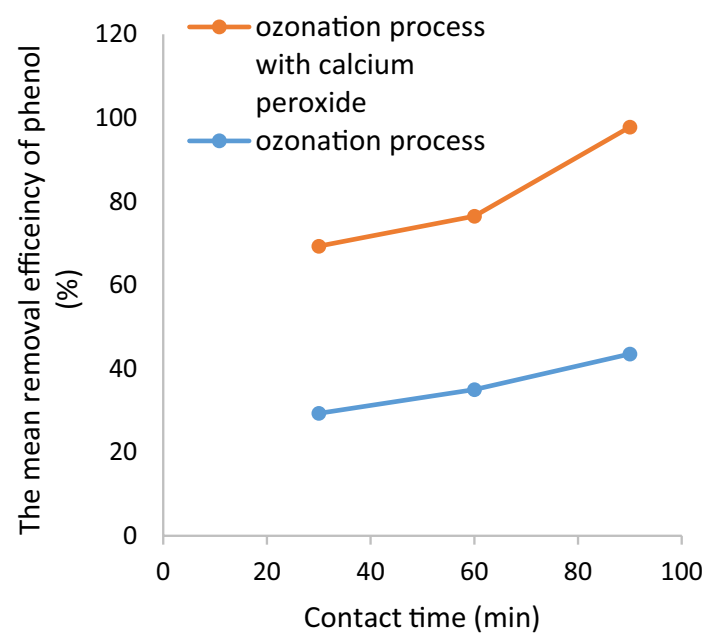

Fig. 6 Effects of ozonation process alone and ozonation process with calcium peroxide on removal of phenol

\section{Determination of kinetics of phenol degradation}

In order to determine the kinetics of phenol decomposition, the kinetics of the reactions were investigated. According to the results, the kinetics of decomposition follows the pseudo-first-order equation. The first-order equation is shown in Eq. 3.

$\operatorname{Ln}\left(C_{t} / C_{0}\right)=-k_{\text {obs }} t$

$k_{\text {obs }}$ constant first-order decomposition rate $\left(\mathrm{min}^{-1}\right), C_{0}$ initial concentration of phenol $\left(\mathrm{mg} \mathrm{L}^{-1}\right)$.

Correlation coefficient was obtained by calculating $\mathrm{Ln}$ $\left(C_{0} / C_{t}\right)$ against time in different concentrations of phenol. The results obtained from the kinetics study are presented in Table 1.

According to the results, the kinetic of the pseudofirst-order equation follows the correlation coefficients $R^{2}=0.9971$. The results of this study are in line with the results of the studies by Laoufi et al. in 2008 and Yan Huy et al. in 2012 by using the advanced oxidation process in the removal of phenol. These studies show that

Table 1 Results of pseudo-first-order kinetics at different concentrations of phenol

\begin{tabular}{llll}
\hline$C_{0}(\mathrm{mg} / \mathrm{L})$ & $R 2$ & $k_{\text {obs }}(1 / \mathrm{min})$ & Line Eqe \\
\hline 5 & 0.9971 & 0.0421 & $y=0.0421 x-0.0863$ \\
10 & 0.9916 & 0.0257 & $y=0.0257 x-0.1136$ \\
15 & 0.9687 & 0.0176 & $y=0.0176 x-0.1098$ \\
20 & 0.9592 & 0.0103 & $y=0.0103 x-0.0383$ \\
\hline
\end{tabular}

decomposition kinetics of phenol follows pseudo-firstorder kinetic (Laoufi et al. 2008).

\section{Determination of phenol degradation thermodynamics}

The constant thermodynamic equilibrium $\left(\mathrm{K}^{\circ}\right)$ for temperature variations can be used to calculate the functions of thermodynamic, such as enthalpy changes and standard entropy $\left(\Delta \mathrm{H}^{\circ}\right.$ and $\Delta \mathrm{S}^{\circ}$ ), as well as the standard energy-change based on Gibbs changes $\left(\Delta \mathrm{G}^{\circ}\right)$.

$\Delta G=-R T \operatorname{Ln} K$

$k=\frac{q e}{c e}$

$\operatorname{Lnk}^{\circ}=-\frac{\Delta H^{\circ}}{R}\left(\frac{1}{T}\right)+\frac{\Delta S}{R}$

In these relations, $R, T$ and $K^{0}$ are the total gas concentration $(8.314 \mathrm{~J} / \mathrm{K} \mathrm{mol})$, the absolute temperature $(\mathrm{K})$ and the distribution coefficient, respectively. $\Delta \mathrm{H}$ and $\Delta \mathrm{S}$ could be calculated from the slope and intercept of linear plot of in $\mathrm{K}$ versus $1 / \mathrm{T}$. With the aid of Eq. (6) and the $\mathrm{LnK}^{\circ}$ replacement to $1 / \mathrm{T}$, we can obtain the enthalpy changes and standard entropy from the gradient and width of the origin of the drawn line, respectively. The thermodynamic variables are shown in Table 2.

According to the results, the enthalpy is positive and the standard entropy is negative. Also changes in the Gibbs free energy will increase with increasing temperature.

The positive value of $\Delta \mathrm{H}^{\circ}$ and negative $\Delta \mathrm{S}^{\circ}$, respectively, indicates the thermostability in the process of phenol decomposition with ozonation and calcium peroxide. The evaluation of free energy changes in the Gibbs Standard also shows that the phenol decomposition was acquired at $25^{\circ} \mathrm{C}$. This temperature was the optimum temperature and with increasing temperature, the degradation conditions would be unfavorable, and the spontaneous reaction would be reduced. Thermodynamic studies show that phenol decomposition with ozonation and calcium peroxide is an endothermic process.

Table 2 The thermodynamic variables

\begin{tabular}{llll}
\hline $\begin{array}{l}\text { Temperature } \\
\left(\mathrm{k}^{\circ}\right)\end{array}$ & $\Delta \mathrm{G}^{\circ}(\mathrm{KJ} / \mathrm{mol})$ & $\Delta \mathrm{H}^{\circ}(\mathrm{KJ} / \mathrm{mol})$ & $\Delta \mathrm{S}^{\circ}(\mathrm{J} / \mathrm{mol})$ \\
\hline 298 & 17.29 & 8.6 & -21.117 \\
308 & 15.34 & & \\
318 & 14.68 & & \\
\hline
\end{tabular}




\section{Removal of phenol from real wastewater}

The quality of Zarand coal washing factory's sewage after adding phenol as optimum conditions is shown in Table 3 .

After determining the quality of Zarand coal washing factory's sewage, the amount of phenol in the real sample was less than optimal conditions and was added manually to the real sample in order to bring the amount of phenol to optimal conditions. In optimal conditions, the phenol removal efficiency for real sample was $87 \%$, and its efficiency was less than the synthetic sample. Also, COD reduction was obtained as $65.4 \%$ for the real sample.

Maximum removal efficiencies of phenol and COD by ozonation process with calcium peroxide under optimal conditions including contact time of $90 \mathrm{~min}, \mathrm{pH}=3$, phenol concentration of $5 \mathrm{mg} / \mathrm{L}$, concentration of $0.025 \mathrm{mg} / \mathrm{L}$ of calcium peroxide in real sample were 87 and $65.4 \%$, respectively. There was a decrease in the removal efficiency of phenol in Zarand coal washing factory's sewage. This decrease in removal efficiency was due to impurities in real sample, including turbidity, TSS and sulfate ion. The sulfate ion combines with free hydroxyl radicals, and they are converted into mineral hydroxyl radicals. Because the power of

mineral hydroxyl radical is much lower than free hydroxyl radicals, the phenol removal efficiency in the real sample is less than the synthetic sample.

\section{Degradation of phenol}

According to study of articles about degradation and removal of phenol by advanced oxidation processes, it can be concluded that the phenol eventually decomposes into water and carbon dioxide. According to Fig. 7, phenol is first oxidized to catechol and hydroquinone and then oxidizes to o-benzoquinone and p-benzoquinone, respectively. By $\mathrm{OH}$ radicals and $\mathrm{O}_{3}$, aromatic rings are broken down into organic acids. Then o-benzoquinone and p-benzoquinone are decomposed into organic acids such as oxalic acid, propionic acid, formic acid and acetic acid, and eventually these organic acids oxidize to $\mathrm{H}_{2} \mathrm{O}$ and $\mathrm{CO}_{2}$ (Pimentel et al. 2008; Suzuki et al. 2015; Yang et al. 2010; Li et al. 2005; Chiou et al. 2008).

\section{Discussion}

Table 3 Quality of COD, TSS, $\mathrm{pH}$ and phenol of Zarand coal washing factory's sewage

\begin{tabular}{ll}
\hline Parameter & Amount \\
\hline COD & $315 \mathrm{mg} / \mathrm{L}$ \\
Phenol & $1.332 \mathrm{mg} / \mathrm{L}$ \\
TSS & $136 \mathrm{mg} / \mathrm{L}$ \\
$\mathrm{pH}$ & 8.1 \\
\hline
\end{tabular}

\section{Effect of $\mathrm{pH}$}

The removal efficiency decreased with increasing $\mathrm{pH}$, because in acidic condition calcium peroxide reacted with $\mathrm{H}^{+}$and produced hydrogen peroxide according to Eqs. 7-15 (Rahmani et al. 2018; Azizah and Widiasa 2018).

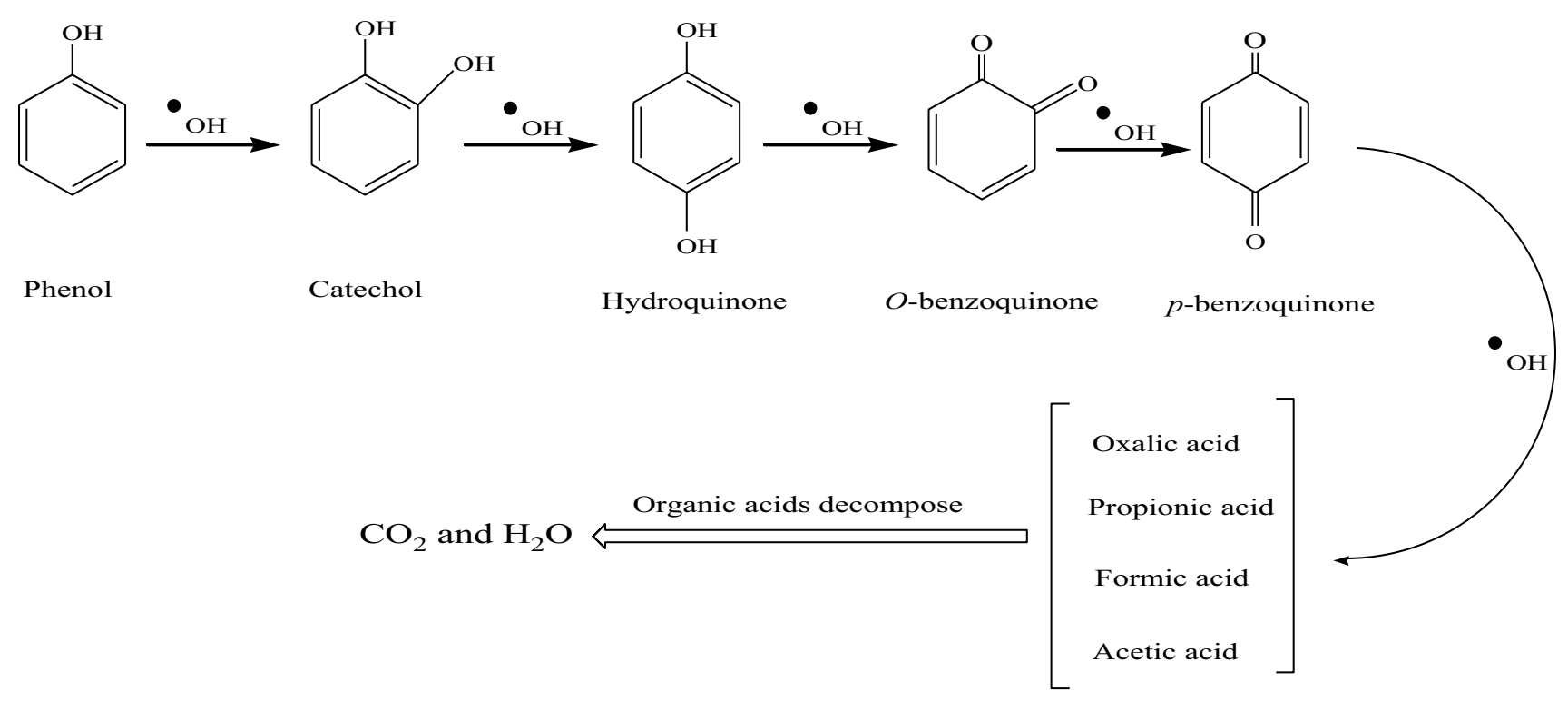

Fig. 7 Reaction pathway of phenol degradation by AOP 


$$
\begin{aligned}
& \mathrm{CaO}_{2}+2 \mathrm{H}^{+} \rightarrow \mathrm{Ca}_{2}+(\mathrm{aq})+2 \mathrm{H}_{2} \mathrm{O}_{2} \\
& \mathrm{OH}^{\mathrm{o}}+\mathrm{H}_{2} \mathrm{O}_{2} \rightarrow \mathrm{H}_{2} \mathrm{O}+\mathrm{HO}_{2} \\
& \mathrm{OH}^{\mathrm{o}}+\mathrm{HO}_{2} \rightarrow \mathrm{H}_{2} \mathrm{O}+\mathrm{O}_{2} \\
& \mathrm{HO}_{2}+\mathrm{HO}_{2} \rightarrow \mathrm{H}_{2} \mathrm{O}_{2}+\mathrm{O}_{2} \\
& \mathrm{O}_{3}+\mathrm{OH}^{-} \rightarrow \mathrm{HO}_{2}^{-}+\mathrm{O}_{2} \\
& \mathrm{O}_{3}+\mathrm{HO}_{2}^{-} \rightarrow \mathrm{O}_{3}^{-}+\mathrm{HO}_{2} \\
& \mathrm{O}_{3}+\mathrm{H}^{+} \rightarrow \mathrm{HO}_{3} \\
& \mathrm{HO}_{3} \rightarrow \mathrm{OH}+\mathrm{O}_{2} \\
& \mathrm{O}_{3}+\left(\mathrm{H}_{2} \mathrm{O}\right) \rightarrow \mathrm{OH}+\mathrm{O}_{2}+\mathrm{OH}^{-}
\end{aligned}
$$

The results of this study are in line with the results of the studies carried out by Qian et al. in 2013 in China where calcium peroxide was used in removing toluene (Qian et al. 2013), Northup et al. in 2008 in USA for modification of fenton method by calcium peroxide (Northup and Cassidy 2008), Roma et al. in 2011 in England for removal of ciprofloxacin by $\mathrm{UV} / \mathrm{H}_{2} \mathrm{O}_{2}$ method (Roma et al. 2011) and Khan et al. in 2010 in South Korea for tetracycline degradation by ozonation in the aqueous phase (Khan et al. 2010). Calcium peroxide has stability and high solubility in low $\mathrm{pH}$ and produces hydrogen peroxide (Rahmani et al. 2018). Therefore, the main purpose of using calcium peroxide is to produce hydrogen peroxide.

\section{Effect of calcium peroxide concentration}

Ozone can decompose to oxygen by split to radical such as hydroxyl radical $\mathrm{OH}^{\mathrm{o}}$ and super oxide $\left(\mathrm{O}_{2}^{-}\right)$(WijannatrongI et al. 2013). The radical that occurs is very strong oxidant to react with various substances. The mechanism of ozone decomposition with hydrogen peroxide was shown in Eq. (3) that cause product of hydroxyl radicals. Simultaneously, Eqs. (16 to 18) are also involved in the aquatic solution that reduces the efficiency of the process when increasing the presence of hydroxyl radicals in the solution (Rahmani et al. 2018):

$$
\begin{aligned}
& \mathrm{OH}^{\mathrm{o}}+\mathrm{H}_{2} \mathrm{O}_{2} \rightarrow \mathrm{H}_{2} \mathrm{O}+\mathrm{HO}_{2}^{\mathrm{o}} \\
& \mathrm{OH}^{\mathrm{o}}+\mathrm{HO}_{2} \rightarrow \mathrm{H}_{2} \mathrm{O}+\mathrm{O}_{2} \\
& \mathrm{HO}_{2}^{\mathrm{o}}+\mathrm{HO}_{2} \rightarrow \mathrm{H}_{2} \mathrm{O}_{2}+\mathrm{O}_{2}
\end{aligned}
$$

Removal efficiency of phenol was decreased when the calcium peroxide concentration was increased. The results of this study are consistent with the results of the studies by Rahmani et al.in 2015 in Iran about the efficiency of ciprofloxacin removal by ozonation process with calcium peroxide from aqueous solutions (Rahmani et al. 2018) and Malakootian et al. (2016) in Iran where ozonation process with calcium peroxide was used for the removal of metronidazole antibiotic from aqueous solutions (Honarmandrad et al. 2017). The high presence of oxidant in the environment reduces radicals and converts the oxidant radicals to intermediate substances and other compounds (Olyaie et al. 2012).

\section{Effect of phenol concentration}

Removal efficiency was decreased when the initial phenol concentration was increased. The results of this study are in line with the results of the studies by Olyaie et al. (2012) in Iran where arsenic contamination was removed from aqueous solutions by calcium peroxide nanoparticles, Bahrami et al. (2014) in Iran where metronidazole was removed from aqueous solution using ozonation process, Sidmohammadi et al. (2016) in Iran where phenol was removed by using modified zolite (Clinoptilolite) with $\mathrm{FeCl}_{3}$ from aqueous solutions (Seid-Mohammadi et al. 2016) and Nurul Azizah et al. (2018) in Indonesia by using AOPs Refinery Wastewater Treatment Contains High Phenol Concentration (Azizah and Widiasa 2018).

With an increase in the concentration of pollutants, oxidizing materials such as the ozone molecule and hydroxyl radical increase. When the concentration of pollutants is lower, the removal efficiency is increased and the breakdown of pollutants will be complete and the production of intermediate materials will be less (Rahmani et al. 2018).

\section{Effect of contact time}

Removal efficiency increased when contact time was increased. The results of this study are in line with the results of the studies by Bahrami et al. (2014) in Iran, Sidmohammadi et al. (2016) in Iran and Barrocas et al. (2017) in Portugal where titanate nanofibers were sensitized with $\mathrm{ZnS}$ and $\mathrm{Ag}_{2} \mathrm{~S}$ nanoparticles as novel photocatalysts. As contact time increases, the production of hydroxyl radical and ozone molecule is increased. Finally, the removal efficiency was increased. 


\section{Conclusions}

The removal efficiencies of phenol and COD under optimal conditions $\mathrm{pH}=3$, phenol concentration $=5 \mathrm{mg} / \mathrm{L}, \mathrm{CaO}_{2}$ concentration $=0.025 \mathrm{mg} / \mathrm{L}$, temperature $25 \mathrm{C}^{\circ}, 1 \mathrm{~g} / \mathrm{min}$ ozonation rate and contact time $=90 \mathrm{~min}$ in synthetic and real samples (Zarand coal washing factory in Kerman) were obtained $97.8 \%, 87 \%$ and $80 \%, 65.4 \%$, respectively. The kinetics of phenol decomposition follows from the pseudo-first-order equation. Thermodynamic studies show that phenol decomposition with ozonation and calcium peroxide was an endothermic process.

The use of ozonation process with calcium peroxide is a good method due to the high removal efficiency of phenol and advantages such as strong oxidation, decomposition of resistant organic compounds and can be recommended as an efficient method for the removal of phenol from industrial wastewater.

Acknowledgements This research with plan number 96010117 was carried out with the financial support of Iran National Science Foundation (INFS). Hereby, we appreciate the financial support of Iran National Science Foundation (INFS) for this study.

Funding The author(s) received Iran National Science Foundation (INFS) (Grant No. 96010117) funding for this work.

\section{Compliance with ethical standards}

Conflict of interest The authors declare that they have no conflict of interest and are mutually agreed on the publication of this work.

Open Access This article is licensed under a Creative Commons Attribution 4.0 International License, which permits use, sharing, adaptation, distribution and reproduction in any medium or format, as long as you give appropriate credit to the original author(s) and the source, provide a link to the Creative Commons licence, and indicate if changes were made. The images or other third party material in this article are included in the article's Creative Commons licence, unless indicated otherwise in a credit line to the material. If material is not included in the article's Creative Commons licence and your intended use is not permitted by statutory regulation or exceeds the permitted use, you will need to obtain permission directly from the copyright holder. To view a copy of this licence, visit http://creativecommons.org/licenses/by/4.0/.

\section{References}

Agustina T, Ang H, Vareek V (2005) A review of synergistic effect of photocatalysis and ozonation on wastewater treatment. J Photochem Photobiol, C 6:264-273

Azizah AN, Widiasa N (2018) Advanced oxidation processes (AOPs) for refinery wastewater treatment contains high phenol concentration. In: MATEC.

Bahrami F, Kermani M, Farzadkia M, Esrafili A, Arian S, Mokammel A (2014) Removal of metronidazole from aqueous solution using ozonation process. J Mazandaran Univ Med Sci 25:131-140

Barrocas B, Entradas T, Monteiro NC, O, (2017) Titanate nanofibers sensitized with $\mathrm{ZnS}$ and $\mathrm{Ag}_{2} \mathrm{~S}$ nanoparticles as novel photocatalysts for phenol removal. Appl Catal B 218:709-720

Bautitz I, Nogueira R (2007) Degradation of tetracycline by photofenton process-solar irradiation and matrix effects. J Photochem Photobiol Chem 187:33-39

Busca G, Berardinelli S, Resini C, Arrighi L (2008) Technologies for the removal of phenol from fluid streams: a short review of recent developments. J Hazard Mater 160:265-288

Cassidy D, Irvine R (1999) Use of calcium peroxide to provide oxygen for contaminant biodegradation in a saturated soil. J Hazard Mater 69:25-39

Chiou CH, Wu CY, Juang RS (2008) Influence of operating parameters on photocatalytic degradation of phenol in $\mathrm{UV} / \mathrm{TiO}_{2}$ process. Chem Eng J 139:322-329

Gharaghani M, Malakootian M (2017) Photocatalytic degradation of the antibiotic ciprofloxacin by $\mathrm{ZnO}$ nanoparticles immobilized on a glass plate. Deswater 89:304-314

Honarmandrad Z, Malakootian M (2018) Investigating the use of ozonation process with calcium peroxide for the removal of reactive blue 19 dye from textile wastewater. Deswater 118:336-341

Honarmandrad Z, Malakootian M, Asadipour A (2017) Investigating the use of ozonation process with calcium peroxide for the removal of metronidazole antibiotic from aqueous solutions. Deswater 77:315-320

Idris A, SADE K, (2002) Degradation of phenol in wastewater using anolyte produced from electrochemical generation of brine solution. Global Nest 4:139-144

Jamshidi N, Torabian A, Azimi A, Bidhendi G, Jafarzadeh M (2009) Investigation of phenol removal in aqueous solutions using advanced photochemical oxidation (AOP). J Water Wastewater $4: 24-9$

Khan M, Bae H, Jung J (2010) Tetracyclin degradation by ozonation in the aqueous phase: proposed degradation intermediates and phathway. J Hazard Mater 181:659-665

Khodaveisi J, Banejad H, Afkhami A, Olyaie E, Lashgari S, Dashti R (2011) Synthesis of calcium peroxide nanoparticles as an innovative reagent for in situ chemical oxidation. J Hazard Mater 192:1437-4023

Kidak R, Ince N (2007) Catalysis of advanced oxidation reactions by ultrasound: a case study with phenol. J Hazard Mater 146:630-635

Laoufi N, Tassalit D, Bentahar F (2008) The degradation of phenol in water solution by $\mathrm{TiO} 2$ photocatalysis in a helical reactor. Global NEST Journal 10:404-418

Leitão A, Duarte M, Oliveira J (2007) Degradation of phenol by a halotolerant strain of Penicillium chrysogenum. Int Biodeterior Biodegradation 59:220-225

Li XY, Cui YH, Feng YJ, Xie ZM, Gu JD (2005) Reaction pathways and mechanisms of the electrochemical degradation of phenol on different electrodes. Water Res 39:1972-1981

Malakootian M, Dowlatshahi S, Cholicheh M (2013) Reviewing the photocatalytic processes efficiency with and without hydrogen peroxide in cyanide removal from aqueous solutions. $\mathbf{J}$ Mazandaran Univ Med Sci 23:69-78

Malakootian M, Olama N, Malakootian M, Nasiri A (2018) Photocatalytic degradation of metronidazole from aquatic solution by $\mathrm{TiO}_{2}$-doped $\mathrm{Fe}^{3+}$ nano-photocatalyst. Int J Environ Sci Technol 16: 4275-4285.

Malakootian M, Pourshaban-mazandarani M, Hossaini H, Ehrampoush M (2016) Preparation and characterization of $\mathrm{TiO}_{2}$ incorporated $13 \mathrm{X}$ molecular sieves for photocatalytic removal of 
acetaminophen from aqueous solutions. Process Saf Environ Prot 104:334-345

Malakootian M, Yaghmaeian K, Momenzadeh R (2015) Efficiency of titanium dioxide photocatalytic activity in removing anionic surfactant of sodium dodecyl sulfate from waste water. Koomesh 16:648-654

Manojlovic D, Ostojic D, Obradovic B, Kuraica M, Krsmanovic V, Puric J (2007) Removal of phenol and chlorophenols from water by new ozone generator. Desalination 213:116-122

Northup A, Cassidy D (2008) Calcium peroxide $\left(\mathrm{CaO}_{2}\right)$ for use in modified Fenton chemistry. J Hazard Mater 152:1164-1170

Olyaie E, Banejad H, Afkhami A, Rahmani A, Khodaveisi J (2012) Development of a cost-effective technique to remove the arsenic contamination from aqueous solutions by calcium peroxide nanoparticles. Sep Purif Technol 95:5-10

Pimentel M, Oturan N, Dezotti M, Oturan M (2008) Phenol degradation by advanced electrochemical oxidation process electroFenton using a carbon felt cathode. Appl Catal B 83:140-149

Qian Y, Zhou X, Zhang Y, Zhang W, Chen J (2013) Performance and properties of nanoscale calcium peroxide for toluene Removal. Chemosphere 91:717-723

Rahmani A, Nematollahi D, Samarghandi M, Samadi M, Azarian G (2018) A combined advanced oxidation process: electrooxidationozonation for antibiotic ciprofloxacin removal from aqueous solution. J Electroanal Chem 808:82-89

Roma M, Weller M, Wentzell S (2011) Removal of ciprofloxacin from water using adsorption, $\mathrm{UV}$ photolysis and $\mathrm{UV} / \mathrm{H}_{2} \mathrm{O}_{2}$ degradation

Roostaei N, Tezel F (2004) Removal of phenol from aqueous solutions by adsorption. J Environ Manage 70:157-164

Sarmah A, Meyer M, Boxall A (2006) A global perspective on the use, sales, exposure pathways, occurrence, fate and effects of veterinary antibiotics (VAs) in the environment. Chemiosphere 65:725-59

Seid-mohammadi A, Almasi H, Asgari G, Leili M, Sharifi Z (2016) The study of phenol removal from aqueous solutions using oxidizing agents of peroxide hydrogen. Persulfate Periodate Act Ultrasound, JRUMS 15:835-848

Sun H, Yaoa J, Li D, Li Q, Liu B, Liu S (2017) Removal of phenols from coal gasification wastewater through polypropylene hollow fiber supported liquid membrane. Chem Eng Res Des 123:277-283

Suzuki H, Araki S, Yamamoto H (2015) Evaluation of advanced oxidation processes (AOP) using $\mathrm{O}_{3}, \mathrm{UV}$, and $\mathrm{TiO}_{2}$ for the degradation of phenol in water. J Water Process Eng 7:54-60

Tryba B, MorawskI A, Inagaki M (2003) Application of $\mathrm{TiO}_{2}$-mounted activated carbon to the removal of phenol from water. Appl Catal B 41:427-433

Wijannatrongi S, Aroonsrimorakot S, Thavipoke P, Sagjan S (2013) Removal of reactive dyes from textile dyeing industrial effluent by ozonation process. APCBEE Procedia 5:279-282

Xiao M, Zhou J, Tan Y, Zhang A, Xia Y, JI L, (2006) Treatment of highly-concentrated phenol wastewater with an extractive membrane reactor using silicone rubber. Desalination 195:281-293

Yang L, Hu W, Huang H, Yan B (2010) Degradation of high concentrationphenol by ozonation in combination with ultrasonic irradiation. Deswater 21:87-95

Publisher's Note Springer Nature remains neutral with regard to jurisdictional claims in published maps and institutional affiliations. 